\title{
Lógistica reversa de veículos no fim de vida: a realidade com vistas à sustentabilidade ambiental
}

Reverse vehicle logistics at the end of life: the reality with a viev to environmental sustainability

Recibido: octubre 20 de 2019 | Revisado: noviembre 10 de 2019 | Aceptado: diciembre 17 de 2019

\author{
José A. Rodríguez Melquiades ${ }^{\mathrm{I}}$ \\ LuCinei Tavares de Assunção ${ }^{2}$ \\ Aline MaIA ${ }^{3}$ \\ Gerardo Pereira de Sousa ${ }^{4}$
}

\begin{abstract}
Resumo
O descarte dos veículos em fim de vida impacta direta ou indiretamente, o meio ambiente em função dos resíduos de fabricação. Uma alternativa para diminuir esse problema é a logística reversa de veículos, por ser considerada uma técnica inovadora de reuso, remanufatura e reciclagem destes bens na indústria e mercado automobilísticos. O objetivo deste artigo é apresentar as experiências internacionais e seus resultados como propostas de soluçáo para o descarte dos veículos em fim de vida, e os desafios do Brasil para aprovar leis que regulamentam essa atividade no país..
\end{abstract}

Palavras chave: logística reversa, sustentabilidade, veículos em fim de vida

\begin{abstract}
The disposal of end of life vehicles directly or indirectly impacts the environment in terms of manufacturing waste. An alternative to reduce this problem is reverse logistics vehicle considered an innovative technique for reuse, remanufacturing and recycling of these goods in the automobile industry and market. The objective of this paper is to present the international experiences and results as proposed solutions for the disposal of end of life vehicles, and the challenges of Brazil to pass laws that regulate this activity in the

$$
\text { country. }
$$
\end{abstract}

Key words: reverse logistics, sustainability, end of life vehicles

\footnotetext{
1 Universidad Nacional de Trujillo, jrodriguez@unitru.edu.pe.

2 Universidade de Brasília, lucaengenharia@ hotmail.com.

3 Universidade de Brasília, alinemaia_geo@ yahoo.com.br.

4 Universidade de Brasília, profgerardo. adm@ufpi.edu.br.
}

\footnotetext{
(C) Los autores. Este artículo es publicado por la Revista Campus de la Facultad de Ingeniería y Arquitectura de la Universidad de San Martín de Porres. Este artículo se distribuye en los términos de la Licencia Creative Commons Atribución No-comercial - Compartir-Igual 4.0 Internacional (https://creativecommons.org/licenses/ CC-BY), que permite el uso no comercial, distribución y reproducción en cualquier medio siempre que la obra original sea debidamente citada. Para uso comercial contactar a: revistacampus@usmp.pe.
} 


\section{Introduçáo}

$\mathrm{O}$ rápido crescimento populacional nas áreas urbanas faz aumentar a complexidade dos problemas já existentes nas médias e grandes cidades. Um desses problemas é a poluição do meio ambiente e a degradaçáo ambiental, devido ao crescimento do uso de bens, cujos resíduos de fabricação são, na maioria das vezes, mal dispostos na natureza.

O veículo, um dos mais desejados bens de consumo, tem despertado preocupaçōes acerca da quantidade produzida e dos seus impactos na qualidade de vida das populaçóes. Dentre outros impactos negativos causados pela quantidade excessiva de veículos fabricados no mundo, destaca-se o problema de descarte desses bens após atingirem seu final de ciclo de vida, ou seja, com aproximadamente 20 anos de uso.

Quando um produto, como por exemplo, veículos velhos, após o seu consumo é mal disposto na natureza, traz efeitos negativos ao meio ambiente. Tais efeitos estão sendo minimizados por meio de propostas qualitativas tais como, diretivas publicadas no Jornal Oficial (2000) sobre a Diretiva 2000/53/CE, onde o veículo que constitui um resíduo na acepção da Diretiva 75/442/CEE é definido como Veículos em Fim de Vida (VFV), para tentar contribuir com a sustentabilidade do meio ambiente por meio das disposiçôes para a comunidade europeia. Em geral a vontade do usuário ou dono do veículo é quem designa VFV, mas em certos casos um veículo é considerado VFV de acordo com a condiçáa que ele se encontra (Environment, 2008).
Vale ressaltar que a liberação de resíduos tóxicos e a contaminação do solo, da água e do ar são alguns dos impactos negativos provocados por veículos abandonados em final do seu ciclo de vida, o que ocasiona graves problemas ao meio ambiente. Essa situação tem provocado um questionamento sobre o que fazer para amenizar estes impactos e contribuir para a sustentabilidade ambiental.

Nesta perspectiva, a logística reversa constitui uma ferramenta que auxilia no processo de recuperaçáo das partes dos veículos para que possam ser transportadas aos centros especializados e sejam recicladas, reutilizadas ou direcionadas para os aterros sanitários adequados e náo apenas para os lixóes.

Os vários problemas ambientais, provocados pelo descarte inadequado de veículos em final de ciclo de vida, estão estimulando a prática de logística orientada para o reaproveitamento de produtos pós-consumo. $\mathrm{O}$ processo logístico reverso se dá por meio do retorno de materiais reaproveitáveis, a exemplo do aço, cobre, alumínio, magnésio, plásticos, borracha, vidros, dentre outros.

Como os impactos ambientais do descarte de veículos se dão, em sua maioria, nos grandes e médios centros urbanos, a logística reversa é, portanto, de fundamental importância para que as cidades minimizem essa situação. Assim, o planejamento e implementaçáo de sistemas logísticos para as atividades de coleta, triagem e processamento para assegurar uma recuperaçáo sustentável tem cada dia maior importância 
(Srivastava, 2008; Lee J. et al., 2009; Lee J. et al., 2010; Lambert et al., 2011; El Korchi, 2011).

Este artigo está organizado em cinco seções nas quais serão discutidos os conceitos de sustentabilidade e meio ambiente; logística reversa e a sustentabilidade ambiental; as experiências internacionais na aplicabilidade desta técnica; os desafios do Brasil para aprovação de leis que regulamentem esta atividade $\mathrm{e}$ as consideraçôes finais.

\section{Sustentabilidade e meio ambiente}

$\mathrm{O}$ século XX se define como uma era de decomposição, e o futuro como desconhecido e problemático, devido à avançada degradação ambiental em que o planeta se encontra (Hobsbaw, 2000). Atualmente um dos grandes desafios do homem é continuar promovendo o crescimento econômico sem comprometer os recursos para as futuras geraçóes.

Neste contexto, devido aos vários problemas ambientais ocasionados pela ação predatória do homem sobre a natureza, surge uma emergencial preocupaçáo de pesquisadores $\mathrm{e}$ acadêmicos em vários países no sentido de conhecer os conceitos de sustentabilidade e de que forma suas práticas contribuem para uma melhor qualidade de vida das populaçóes em todo o planeta.

Dentre as várias definiçôes existentes sobre sustentabilidade, (Afonso, 2006) estabelece que o termo implique na manutenção quantitativa e qualitativa do estoque de recursos ambientais, em que tais recursos são utilizados de forma a não danificar suas fontes ou limitar a capacidade de suprimento para que as necessidades, tanto atuais quanto futuras sejam igualmente satisfeitas. Essa definição deriva-se do conceito de desenvolvimento sustentável, fruto de reflexóes e debates ocorridos desde a década de 1960.

Reportando ao Brasil, discussóes acerca da questão ambiental se intensificam nos debates e estudos, após uma fase de intenso crescimento urbano. Com a crise do petróleo no final dos anos sessenta e início da década de setenta, a reflexáo relacionada ao futuro, que se apresenta incerto, começa a ser exposta no pensamento político, social e filosófico levando ao questionamento da participação do homem no planeta. Questóes como poluição do ar e da água e aumento da populaçáo nas cidades acarretam ainda mais tais problemas, resultando na escassez de recursos naturais (Zarei et al., 2010).

Uma análise dos meios de transporte e como este vem sendo largamente utilizado pela população, pode facilmente demonstrar a necessidade de projetos de desenvolvimento sustentável. Os veículos automotores (automóveis, caminhóes, motocicletas) são os principais meios de transportes de pessoas e mercadorias em todo o mundo e estes veículos são responsáveis pela emissão de boa parte dos gases que poluem o ar que respiramos.

Segundo informações a fabricação mundial de carros subiu para 86 milhóes de unidades em 2018, menos 0,5\% que em 2017 foi de 86,43 milhóes. No Brasil, foram vendidos cerca de 2.566.235 milhóes. Ainda de acordo com a FENABRAVE (2019) o mercado 
apresentou alta de 14,6\% em comparação com às vendas de 2017 e segundo a DENATRAN (2020) em novembro 2019 Brasil tive 104.413.498 veículos.
A Figura 1 apresenta o crescimento da quantidade de veículos em Brasília DF. Assim, até novembro de 2019 existiam 1.876 .875 veículos.

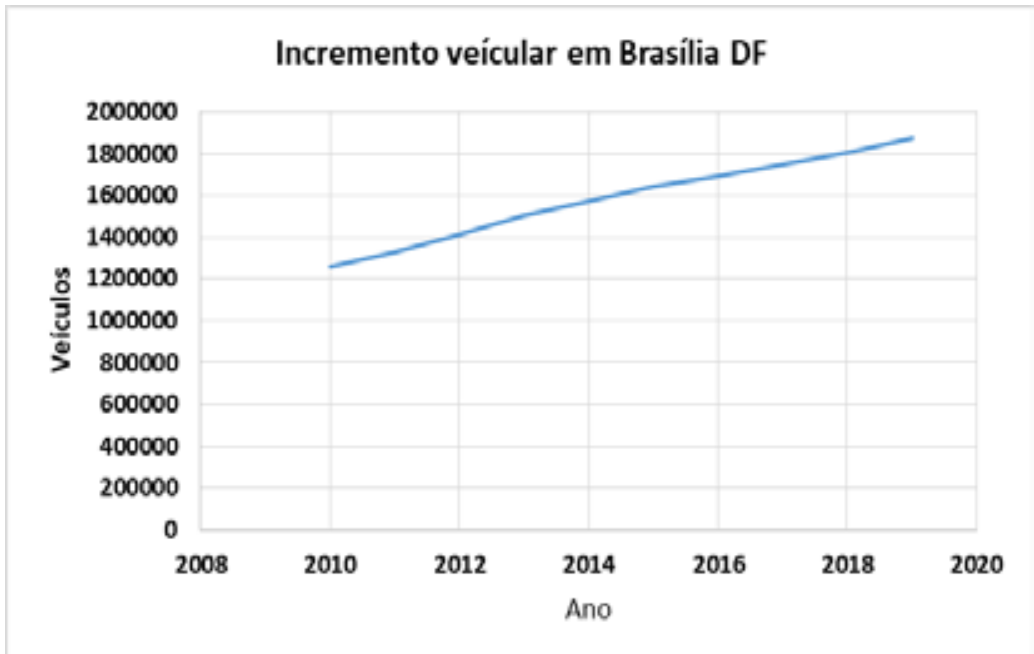

Figura 1. Crescimento de veículos em Brasília DF

Fonte: DENATRAN (2020)

A busca da sustentabilidade na produção, comercialização e no pósconsumo de veículos VFV requer estratégias de planejamentodelongo prazo, o que vai de encontro ao neoliberalismo que incentivam práticas de mercado para obtenção do maior lucro possível em curtos espaços de tempo, o que pode impactar negativamente o meio ambiente. Diante das estatísticas apresentadas sobre o crescimento do consumo de veículos pela sociedade, observa-se uma preocupação sobre a destinação destes veículos após o seu tempo de fim de vida. Nesta perspectiva, a logística reversa surge como uma contribuição para a sustentabilidade ambiental.

\section{Logística reversa e a sustentabilidade ambiental}

A logística deve ser pensada desde a concepçáo do produto passando por todas as fases de produção, transporte e estocagem até chegar aos mercados consumidores: "Logística é o processo de planejamento, implantação e controle do fluxo eficiente e eficaz de mercadorias, serviços e das informaçóes relativas desde o ponto de origem até o ponto de consumo com o propósito de atender às exigências dos clientes" (Ballou, 2006).

A logística reversa, como a área inovadora da logística empresarial, é a que planeja, opera e controla o fluxo e as informaçóeslogísticas correspondentes, do retorno dos bens de pós-venda e de pós - consumo ao ciclo de negócios ou ao ciclo produtivo através dos canais de distribuição reversos, agregando-lhes valor de diversas naturezas: econômico, ecológico, legal, logístico, de imagem corporativa, entre outros (Leite, 2006).

Desde os anos 90, a logística reversa tem recebido novas abordagens. Assim o conceito é o retorno dos produtos, redução de recursos, reciclagem, e ações para substituição e reutilização 
de materiais, disposição final dos resíduos, reaproveitamento, reparação e remanufatura.

Canais reversos ou fluxos reversos já são conhecidos na literatura desde os anos setenta. Assim, no intuito de tentar estabelecer os fundamentos da logística reversa, (De Brito, 2003) faz uma proposta baseada em quatro perspectivas que achou interessante e que devem ter respostas: Por que as coisas voltam? O que está sendo retornado? Como funciona a logística reversa na pratica? E quem está executando as atividades de logística reversa?

Devido à relevância dos debates sobre a importância da sustentabilidade ambiental para a qualidade de vida no planeta, o poder público em vários países tem se manifestado no sentido de criar leis que possam delimitar as responsabilidades dos impactos ambientais entre governo e fabricantes.

Em consonância com esta nova visão o Brasil, por meio da Lei No 12.305, de 02 de agosto de 2010, instituiu a Política Nacional de Resíduos Sólidos, na qual em seu Art. 30 a define como sendo um ato de natureza contratual firmado entre o Poder Público e fabricantes, importadores e distribuidores ou comerciantes, tendo em vista a implantação da responsabilidade compartilhada pelo ciclo de vida do produto o qual, segundo a lei citada, significa uma série de etapas que envolvem o desenvolvimento do produto, a obtenção de matérias-primas e insumos, $\mathrm{o}$ processo produtivo, o consumo e a disposiçáo final adequada.

Dos conceitos apresentados podese deduzir que este tipo de logística é parte do desenvolvimento sustentável e, portanto, ajuda no processo de minimizar as contaminaçôes no meio ambiente. (Figura 2)

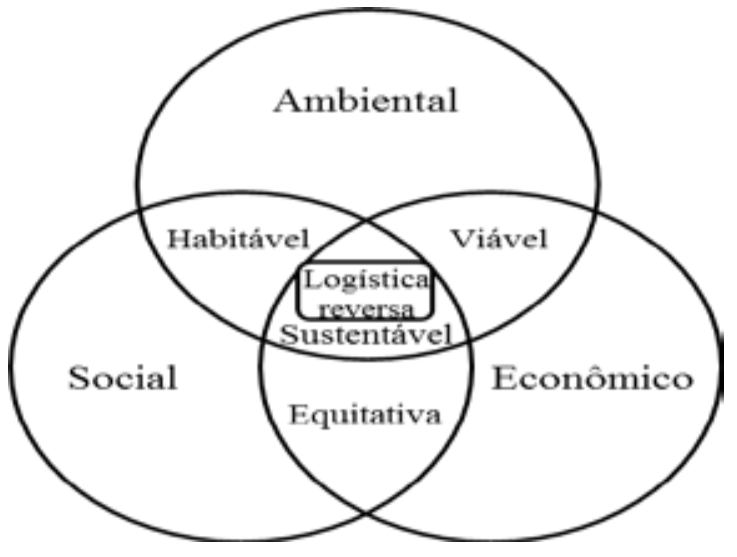

Figura 2. Logística reversa embutida no desenvolvimento sustentável Fonte: Adaptado de Tanguay et al. (2010)

Guarnieri (2011) também considera a sustentabilidade para definir logística reversa e afirma que a mesma trata da operacionalização do retorno dos resíduos de pós-consumo e pós- venda e o gerenciamento do fluxo de informaçóes que ocorre desde o consumidor final até o fabricante, objetivando sua revalorização ou, em última instância, seu descarte ambientalmente adequado, contribuindo assim para a consolidação do conceito de sustentabilidade no ambiente empresarial, apoiada nos conceitos de desenvolvimento ambiental, social e econômico. O processo logístico reverso é ilustrado na Figura 3.

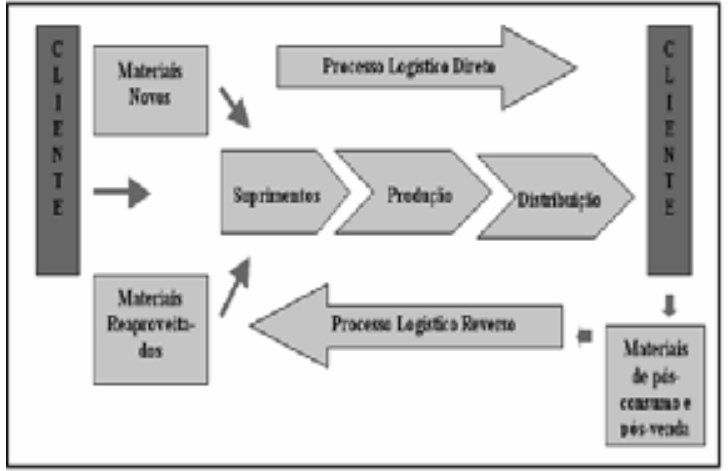

Figura 3. Operacionalização do processo Logístico Reverso

Fonte: Adaptado de Rogers e TibbenLembke por Guarnieri et al. (2011) 
De acordo com OICA - International Organization of Motor Vehicle Manufacturers (2020), a produção mundial de automóveis e veículos comerciais leves foi de 95.634.593 milhóes em 2018 com a tendência de crescimento devido ao aumento populacional e acesso aos bens de consumo. Em Brasil 2.879.809 veículos foram vendidos.

Diante dos números apresentados sobre a quantidade de veículos fabricados e vendidos, surge um questionamento: Qual é a destinação desses bens após atingirem o seu fim de vida útil? Quais medidas estão sendo adotadas? Quais são as possibilidades de aplicação de logística reversa neste mercado?

Por esta razão (Cury et al., 2008)afirma que o setor automobilístico vem estudando seus impactos ambientais eque estaéuma das indústrias com maior potencial poluidor $\mathrm{e}$ maior potencial mitigador de seus impactos através do reuso, remanufatura e reciclagem dos materiais, peças e componentes dos veículos produzidos. Assim sendo, Karagoz et al. (2019) considerando a importância da conservação do meio ambiente e o desenvolvimento sustentável faz uma revisão do gerenciamento de veículos em fim de vida. Os pesquisadores somente focaram apenas na logística reversa, infraestrutura de recuperação, desmontagem, etc. Mas não fizeram uma revisão de modelos matemáticos. Poucas propostas quantitativas foram apresentadas em Harraz (2011); Manzour(2008); Merkisz-Guranowska(2011); MerkiszGuranowska(2012) e Simic (2012).

Deacordocom Rogerse Tibben-Lembke (1999), no final da década de 1990 cerca de nove milhóes de veículos eram descartados anualmente, criando aproximadamente nove milhóes de toneladas de resíduos. Como consequência, em 21 de Outubro de 2000, o parlamento europeu aprovou a Diretiva 2000/53/CE que responsabiliza os fabricantes de veículos pelos resíduos gerados pelos automóveis durante todo seu ciclo de vida, até o momento do descarte. Essa iniciativa favoreceu a aplicabilidade da logística reversa no setor automotivo.

Segundo Hatschbach (2003), para enfrentar esse desafio ambiental a indústria automobilística vem criando amplas inovaçóes tecnológicas que têm alterado o conceito do automóvel e de sua produção. Outro aspecto que tem favorecido o tratamento da dimensão ambiental pela indústria automobilística é a utilização das mesmas peças, sistemas e matérias de forma consorciada por vários modelos.

O Brasil tem uma frota de veículos que já superou 40 milhóes de unidades e apresenta uma taxa crescente de fabricação de novos veículos, além daqueles com idade avançada. Isto traz a futuro problemas ambientais, econômicos e sociais, contribuindo para o aumento da emissáo de poluentes, maior consumo de combustível, acidentes e congestionamentos. Atualmente, o Brasil tem aproximadamente 200 veículos por cada 1000 habitantes. Portanto, a reciclagem do veículo é uma necessidade (Castro, 2020). Dados como estes justificam ainda mais a importância da logística reversa de veículos.

\section{Experiências internacionais na aplicabilidade da logística reversa \\ - A Diretiva Europeia/2000/53/EC e sua Aplicabilidade}

Com base nos conceitos de logística reversa, atualmente os países membros 
da União Europeia (UE) têm adotado práticas a partir da criação da Diretiva Europeia 2000/53/CE, com objetivo de estabelecer como prioridade a prevençáo da formação de resíduos provenientes de VFV.

A gestão do processo de recuperação dos VFV e configuração da infraestrutura necessária receberam crescente atenção à projeção e produção de novos veículos e recuperação dos já utilizados. Os países europeus estáo trabalhando com o intuito de cumprir com a Diretiva. Por esta razão este trabalho apresenta dois casos de aplicabilidade da logística reversa dos VFV um na Espanha e outro na Itália.

\section{- Aplicabilidade da Logística Reversa na Espanha}

A Espanha como membro da UE é um país que segue as normas e leis da Diretiva UE/2000. Foi criado neste país o Centro de Experimentación y Seguridad Vial da seguradora Mapfre (CesviMap) no qual possui um Centro Autorizado de Tratamento (CAT) com espaços licenciados pelo governo, responsáveis por todas as fases de tratamento de veículos para posterior mobilização.

A reciclagem de veículos na Espanha começou a ser regulamentada pelo decreto real 1383/2002 do 20/12/2002. Este decreto sob o VFV foi substituído pelo decreto real do 20/01/2017. Assim um veículo que atingiu o fim de sua vida útil é considerado resíduo a partir do momento em que foi entregue ao centro de tratamento de veículos (CAT) e o certificado de destruiçáo entregado ao proprietário do veículo. Nos CATs os veículos sáo sometidos ao processo de despoluição, depois a desmontagem para a reutilizaçáo e reciclagem das peças, além de outros processos (Comunidad de Madrid, 2018).

Ainda, a lei se estende às montadoras, que devem limitar o uso de substâncias poluentes nos veículos e proporcionar um processo que facilite a desmontagem. Também são responsáveis pela descontaminação, que pode ser repassada para os Centros de Tratamento Autorizados - CATs, por meio de acordos. Conforme a regulamentação, $85 \%$ do veículo deve ser reciclável. A meta foi que, até 2015 , o percentual suba para $95 \%$.

Neste contexto, a atuação do governo se dá no controle das instalações dos centros para que eles cumpram as normas e realizem a descontaminação dos veículos com os materiais adequados. Existem 950 CATs espalhados pelo país e o trabalho realizado por eles vai desde a recepção dos carros classificados pelas companhias de seguros como casos de perda total, após acidentes, até a desmontagem, venda de peças e envio dos resíduos para reciclagem e destinação adequada. Depois de retirados todos os itens aproveitáveis, os centros emitem o certificado de despoluiçáo do veículo. A partir de um abrangente sistema de tecnologia da informação, as peças são cadastradas e recolocadas no mercado com certificado de garantia.

\section{- Aplicabilidade da Logística Reversa na Itália}

A quantidade de veículos processados que correspondem aos 15\% dos veículos desmontados na Europa, um dos maiores produtores de aço, e a grande taxa de reutilização e reciclagem de VFV fazem 
interessante a análise e adoçáo, como exemplo, para América.

O êxito da Itália no processamento dos VFV deve-se a infraestrutura de reciclagem existente e que é formada por 1800 instalaçóes autorizadas e 29 centros de trituração, os quais estão relacionados com a densidade de VFV de cada ano. Ainda mais, isto acontece devido ao cumprimento das disposições da Diretiva 2000/53/EC, tendo como objetivo desde o ano 2008: avaliar a desempenho sobre a reciclagem; melhorar a prevençáo da produção de resíduos perigosos; monitorar os operadores; pesquisar novas tecnologias, tudo de acordo entre o governo e a Associaçáo Nacional dos Montadores, concessionárias e instalaçôes de reciclagem (Berzi et al., 2013).

Com o intuito de diminuir a poluição e manter a sustentabilidade ambiental, na Itália o processo de tratamento dos VFV tem as seguintes etapas: despoluição do veículo executado nas fábricas tais como a drenagem dos fluídos e outros; desmontagem de peças que serão vendidas como peças reutilizadas; desmontagem de peças de metal para serem vendidos como restos de qualidade; desmontagem de fios, plásticos, pneus, vidros e outras partes não metálicas para serem reciclados.

\section{- Aplicabilidade na América Latina}

O gerenciamento dos VFV nos países em desenvolvimento é diferente nos países desenvolvidos, isso porque na maioria países emergentes prioriza-se assuntos econômicos em detrimento dos assuntos ambientais. Falta consciência ambiental. Por esta razão, as suas legislações ainda estáo na fase de ideias e/ou discussóes nos congressos, mas expresso em leis.

\section{- Aplicabilidade da logística reversa na Argentina}

A experiência em logística reversa em reciclagem de veículos na Argentina foi iniciada pelo setor privado no ano de 1995 a partir da criação do Centro Reciclagem de Veículos - CesviAuto. Interessante destacar que o modelo náo nasceu da preocupação ambiental, mas da necessidade de combater os roubos e desmontagem ilegal de veículos, que envolviam cidadãos e a própria polícia.

A regularização começou com o "Operativo Cerrojo" realizado em Buenos Aires para impedir a saída de veículos da regiáo metropolitana. A partir do diálogo entre governo, sociedade e instituiçôes especializadas, foi promulgada, em 2003, a Lei das Autopeças ( $\mathrm{n}^{\circ}$ 25.761), com o intuito de gerir a venda de peças usadas com certificado de garantia.

O CesviAuto foi primeiro centro de reciclagem instalado no país e atende à demanda de empresas parceiras e seguradoras. Como produto final, o centro comercializa autopeças com garantia e sucatas e reciclam 2,3 mil veículos por ano (CNT, 2010).

O processo começa na seguradora que, após a perícia positiva de perda total mecânica ou quando o conserto é financeiramente inviável, emite o registro do sinistro patenteado e encaminha ao centro de reciclagem. $\mathrm{O}$ centro elabora uma relação de peças reutilizáveis e dá início ao processo de reciclagem. As peças reutilizáveis voltam para o mercado e o produto final despoluído é vendido para reciclagem. O governo coordena o setor por meio da Direçáo Nacional de Fiscalizadores. 
De acordo com o gerente-geral do CesviAuto, o faturamento anual do Cesvi argentino é de U\$ 2,3 milhóes. A instituição possui um acordo com as empresas parceiras e seguradoras para a divisão dos ganhos. $\mathrm{O}$ contrato estabelece que $40 \%$ do lucro obtido com a venda das peças voltam ao parceiro. Parte do valor é repassada à vista (25\%), enquanto $15 \%$ do lucro são revertidos em serviços no centro.

\section{- Aplicabilidade da logística reversa no México}

O programa de renovaçáo da frota no México foi fruto de diálogo entre o governo do país e produtores de veículos, com o objetivo de elaborar um sistema para incentivar a compra de veículos novos. O projeto, lançado no ano de 2003, priorizou a retirada de veículos obsoletos em circulação, chamado de Programa de Chatarrización (sucateamento). O usuário entrega o veículo antigo e realiza a compra de um modelo novo ou seminovo com desconto (até seis anos de uso).

Atividades de desmontagem dos veículos velhos são efetuadas por diversas empresas, muitas delas sem tecnologia adequada, pois são simplesmente lojas ou depósitos de sucata que coletam algumas partes. O resto de materiais é enviado para as trituradoras e/ou aterro sanitário. Atividades com estas geram impactos no meio ambiente, pois não existem processos de despoluição (CruzRivera, 2009). Da análise feita pelos pesquisadores na realidade mexicana, identificam regiōes geradoras de VFV, além de fatores que afetam os custos totais na cadeia de suprimentos reversa.

Este fato mostra que as atividades de coleta e distribuição das partes dos VFV é uma gestão ineficiente. Não existe uma política de proteçáo do meio ambiente como consequência dos resíduos gerados pelos automóveis velhos. A sustentabilidade ambiental está em perigo (Cruz-Rivera, 2007) apud (Cruz- Rivera, 2009). A logística reversa nesse país, como em outros países náo desenvolvidos, ainda não contribui com a sustentabilidade ambiental, devido os governos não terem uma visão certa das palavras proteção do meio ambiente. Programas de renovação da frota de veículos náo resolvem o problema, pois a retirada de veículos obsoletos e sua alocação em depósitos sem condições para proteção não favorecem o meio ambiente.

\section{Desafios do Brasil para a} aplicabilidade de logística reversa com vistas à sustentabilidade ambiental

Segundo dados do OICA (2020) o Brasil até o 2018 ocupa a sétima posição no mercado automobilístico mundial na produção total de veículos, atrás apenas da China, Estados Unidos, Japáo, Alemanha, México e Coréia do Sul.

O Brasil necessita ainda, em contraproposta ao ranking de produçáo de veículos, de políticas que atendam aos VFV. Estes deveriam ser destinados ao maior aproveitamento dos materiais recicláveis, conforme alguns projetos de Lei que buscaram e ainda buscam regular o desmonte e as etapas posteriores a esse processo. Cabe lembrar que a Lei do Desmanche $\mathrm{n}^{\circ} 345 / 2007$, que daria forte impulso a reciclagem de veículos, foi vetada pelo Poder Executivo Federal em 2011, sendo o seu veto justificado pela ausência de critérios satisfatórios para regular com segurança a comercializaçáo de autopeças usadas (Castro, 2012). 
Segundo dados da CNT (2010), cerca de 16 milhóes de veículos brasileiros deveriam sair de circulação por terem idade superior a 20 anos, sendo necessária uma política de reaproveitamento e reciclagem no país. No entanto, para isso acontecer necessitava-se uma mudança na legislação brasileira para estimular este tipo de atividade. Existia um projeto de Lei em tramitaçáo no Senado (PLS n ${ }^{\circ} 617$ de 2011) que tem como objetivo disciplinar a desmontagem de veículos automotores terrestres, bem como a comercialização de suas partes e peças para reposição reaproveitáveis, considerando todos os aspectos legais relacionadas à atividade. Além de proteger o meio ambiente e a saúde pública.

Segundo dados publicados pelo Jornal Minas Gerais (2018) publicados em 13/04/2018, entre 2012 e 2017, a idade média dos veículos em circulaçáo envelheceu cerca de um ano. De acordo com a pesquisa, pouco mais da metade da frota $(52 \%)$, ou 22,5 milhôes, tem entre seis e 15 anos de idade. Outros (30\%), ou 12.980.769 milhôes estão com até cinco anos de uso e cerca de (6\%), ou 2.596 .133 milhóes tem mais de 20 anos. Os resultados destes dois parágrafos mostram que aconteceu uma diminuição, mas ainda é consenso entre especialistas que o Brasil precisa ainda melhorar esses indicadores com urgência.

No Brasil a logística reversa é ainda, portanto um desafio. Se reciclada, a frota nacional com idade superior a 20 anos forneceria inúmeros materiais para novos veículos. De acordo com cálculos realizados pelo Cesvi Brasil, os 16 milhóes até 2010 ou 2.596 .133 milhões até 2017 de veículos leves, quando trocados por modelos mais novos e menos poluentes, forneceriam 80 milhôes ou mais de pneus, cuja borracha poderia ser reaproveitada e oito milhôes de toneladas de aço reciclável ou mais.

Importante destacar as iniciativas que ocorrem entre os estados, a exemplo do novo Processo Produtivo Básico - PPB aprovado recentemente para a Zona Franca de Manaus relacionado a temas que incluem a reciclagem de veículos. A iniciativa busca incentivar a reciclagem de resíduos sólidos naquela regiáo: resíduos processados metálicos, plásticos madeira, papelão, vidro e poliestireno expansível. A Portaria Interministerial no 4 de 13 de janeiro de 2012, assinada pelo Ministério da Ciência e Tecnologia (MCTI) juntamente com o Ministério do Desenvolvimento, Indústria e Comércio Exterior (MDIC) define os procedimentos básicos necessários por empresas instaladas na zona franca que queiram usufruir dos incentivos fiscais ali proporcionados.

Castro (2012) apresenta o projeto realizado na Zona Franca de Manaus como iniciativa que pode facilitar $o$ processo de interiorizaçáa $\mathrm{da}$ reciclagem, pois a maioria dos centros se localiza na região sudeste do país. Segundo a visáo do autor, este projeto contribui para um futuro programa de reciclagem de veículos em escala nacional, pois o que temos até o momento são iniciativas de governos estaduais. Além disso, a medida visa estimular a redução de custos para os fabricantes de motocicletas da regiáo, tendo em vista que o alumínio, empregado na fabricação de tanques de combustíveis é um dos produtos que é processado e beneficiado por indústrias regionais e revendido aos fabricantes. 
Observa-se, portanto, que o tratamento adequado dos VFV, principalmente no Brasil, é ainda um problema complexo e de longo prazo. É necessário construir uma estratégia de cooperação entre o Estado, empresas automobilísticas e sociedade que visa estabelecer a infraestrutura necessária para que os projetos de Lei, sejam efetivados e venham a viabilizar a reciclagem dos materiais automotivos e, assim, preservar nossos recursos naturais e nosso meio ambiente para as futuras gerações.

\section{Consideraçóes finais}

Nas últimas décadas foi presenciada uma crescente preocupaçáo com a preservaçáo ambiental em todo o mundo. No Brasil, apesar de náo haver ainda leis que consciência sobre esse tema, tem-se observado inúmeras ações de empresas, organizaçóes náo governamentais, da sociedade civil e até mesmo do governo no sentido de comunicar que o meio ambiente é um bem social e de responsabilidade de todos.

Nesta perspectiva a logística reversa surgiu como alternativa para que a indústria automobilística, uma das maiores do mundo, viesse a repensar suas práticas produtivas no sentido de, também, contribuir para a preservação ambiental.

Logística reversa, portanto, possibilita o reuso, manufatura e reciclagem de VFVs e contribui para o meio ambiente à medida que retiram principalmente dos espaços públicos, veículos que têm provocado vários problemas ambientais já citados. No entanto, essa prática somente tem sido efetiva nos países em que leis específicas para esta atividade foram aprovadas e postas em execução por meio de políticas públicas.

No Brasil, onde a lei para regulamentação de reciclagem de veículos ainda está em tramitação, poucas ações foram realizadas para que se tenham efetivos com relação à prática de logística reversa de veículos em fim de vida. O que se observa, é que o poder público ainda não deu prioridade a este tema no sentido de regular as atividades e incentivar essa prática como estratégia de cunho político, social, econômico e ambiental.

\section{Referências}

Afonso, Cintia M. (2006). Sustentabilidade: caminho ou utopia?. São Paulo: Annablume.

Ballou, R. H.(2006). Gerenciamento da Cadeia de Suprimentos/ Logística Empresarial. $5^{a}$ ed. Porto Alegre: Bookman.

Berzi, L.; Delogu, M.; Giorgetti, A.; Pierini, M. (2013). On-field investigation and process modeling of End-of-Life Vehicles treatment in the context of Italian craft-type authorized treatment facilities. Waste management, Elsevier.

Castro, D. E.; Marques de Souza, V.L.; Gonçalves, A. (2012). Reciclagem e Sustentabilidade na Indústria Automobilística. Belo Horizonte.

Castro, D. E. (2020). A reciclagem de veículos leva a um novo 
modelo econômico sustentável. Despoluir Programa ambiental do transporte. Disponível em http:// www.despoluir.org.br/Artig os/ Detalhe/13. Acesso em 18/01/2020

Confederação Nacional Dos TransportesCNT. (2010). Despoluir - Programa Nacional do Transporte. Seminário Internacional Sobre Reciclagem de Veículos e Renovação de FrotaAs experiências internacionais e os desafios brasileiros.

Comunidad de Madrid (2018). Plan de gestión de vehículos al final de su vida útil. Disponível em https://www. comunidad.madrid/si tes/default/ files/doc/medio-ambiente/8_plan _de_gestion_de_vehiculos_al_ final_de_su_vida_ut il.pdf. Acesso em 18/01/2020.

Cruz-Rivera, R. (2007). The implementation of End-of-Life Vehicles Recycling in developing countries, case study Mexico. $\mathrm{PhD}$ thesis, Doctorate Program at the Chair of Industrial Sustainability at Brandenburg University of Technology in Cottbus, Germany.

Cruz-Rivera, R.; Ertel, J. (2009). Reverse logistics network design for the collection of End-of-Life Vehicles in Mexico. European Journal of Operational Research, Elsevier.

Cury, R.M.; Rodríguez, A. M.; Duarte, P. C.; Mendes, K. B. (2008). Recuperação de Valor em Peças de Veículos em Fim de Vida. Resultados de um Estudo Exploratório. XXVIII Encontro Nacional de Engenharia de Produçáo. Rio de Janeiro.
De Brito, M.; Dekker, R. (2003). A framework for reverse logistics. Research in management, Erasmus research institute of management.

Departamento Nacional de Transito DENATRAN. (2020). Disponível em https://infraestrutura.gov.br/ denatr an. Acesso em 16/01/2020.

Environment. (2008). Diretiva 2008/98/ EC on waste (Waste Framework Directive). Disponível em http:// ec.europa.eu/environment/waste/ framework/. Acesso em 19/01/2020.

El Korchi, A.; Millet, D. (2011). Designing a sustainable reverse logistics channel: the 18 generic structures framework. Journal of cleaner production, Elsevier.

Guarnieri, P. (2011). Logística Reversa: Em busca do equilíbrio econômico e ambiental. Recife: Editora Clube de Autores.

Hatschbach, R. N.; Naveiro, R. M. (2003). Panorama da reciclagem de componentes no setor automobilístico. XXIII ENEGP. Ouro Preto.

Hobsbawm, Eric. (2000). A Era dos Extremos - O breve Século XX 1914-1991. São Paulo: Companbia das Letras.

Harraz, N.; Galal, N. (2011). Network design for end oflife vehicles recovery in countries with developing economy. Int. J. of Sustainable Water and Environmental Systems, volume 3, No 1.

Federação Nacional de Distribuição de Veículos Automotores - 
FENABRAVE. (2019). Disponível em http://www.fenabrave.org.br. Acesso em 15 de janeiro 2020.

International Organization of Motor Vehicle Manufacturers-OICA. (2020). [Dados estatísticos de produção mundial de veículos]. Disponível em: <www.oica.net>. Acesso em 18 de janeiro. 2020

Journal Oficial No L 269 de 21/10/2000. Diretiva 2000/53/CE. Disponível em http://eur- lex.europa. eu/LexUriServ/LexUri Serv. do? uri=CELEX:32000L0053 :PT:HTML. Acesso em 18/01/2020.

Journal de estado de Minas Gerais. Disponível em https://www. e m . com.br/app/noticia/ economia/2018/04/13/internas_e conomia, $951278 /$ frota-deveiculos-no-brasil-cresce-mascontinua-envelhecida.shtml.Acesso em 18/01/2020.

Karagoz, S.; Aydin, N.; Simic, V. (2019). End-of-life vehicle management: a comprenhensive review. Journal of material cycles and waste management, https:// doi.org/10.1007/s101663- 01900945-y. Springer.

Lambert, S.; Riopel, D.; Abdul-Kader, W. (2011). A reverse logistics decisions comceptual framework. Computer $\&$ Industrial engineering, Elsevier.

Leite, P. R. (2006). Logística Reversa: meio ambiente e competitividade. $2^{\circ}$ ed. São Paulo: Pearson Prentice Hall.
Lee, J.; Gen, M.; Rhee, K. (2009). Network model and optimization of reverse logistics by hybrid genetic algorithm. Computer \& Industrial engineering, Elsevier.

Lee, J.; Rhee, K.; Lee, H. (2010). Multiobjetive hybrid genetic algorithm for reverse logistics network design of inventory system with back ordering. Proceedings IEEEM.

Mansour, S.; Zarei, M. (2008). A multiperiod reverse logistics optimization model for end-of-life vehicles recovery based on EU Directive. International journal of Computer Integrated Manufacturing.

Merkisz-Guranowska, Agnieszka (2011). Issues related to the optimization of location of vehicle recycling network entities. The archives of transport, Vol XXII, Issue 3.

Merkisz-Guranowska, Agnieszka (2012). Bicriteria models of vehicles recycling network facility location. The archives of transport, Vol XXIV, Issue 2.

Rogers, D. S; Tibben Lembke, R. S. (1999). Going Backwards: Reverse Logistics Trends and Practices. Reno: University of Nevada.

Tanguay, G.A.; Rajaonson, J.; Lefevre, J.; Lanoie, P. (2010). Measuring the sustainability of cities: An analysis of the use of local indicators. Ecological Indiators, Elsevier.

Simic, V.; Dimitrijevic, B. (2012). Modelling production processes in a vehicle recycling plant. Waste Management \& Research. 
Srivastava, S.K. (2008). Network design for reverse logistics. OMEGA, The International Journal of Management Science, Elsevier.

Zarei, M.; Mansour, S.; Husseinzadeh, A.; Karimi, B. (2010). Designing a reverse logistics for End-of-Life vehicles recovery. Mathematical problems in enginnering, Hindawi Publishing Corporation. 